\title{
Narrativa lésbica mexicana
}

\author{
María Elena O livera Córdova*
}

Resumen:

D esde 1979 con la publicación de E l vampiro de la colonia Roma el tema de la homosexualidad masculina ha encontrado un lugar en la narrativa mexicana; en contraste, la primera novela lésbica se publicó hasta 1989 y su desarrollo ha encontrado mayores enconos y censuras, por lo que apenas a partir del año 2000 han comenzado a escucharse ecos narrativos de esa obra lésbica inicial: A mora de Rosa María Roffiel, poco valorada en los estudios académicos no obstante el importante tiraje y las varias ediciones y reimpresiones nacionales e internacionales. Así pues, la historia del lesbianismo en la narrativa mexicana debe abordarse no sólo desde el análisis literario sino de las determinaciones sociales que han impulsado o censurado su desarrollo hasta nuestros días.

Palabras clave:

Narrative lésbica, novela lésbica, estudios de género en la narrativa contemporánea, Rosa María Roffiel.

*Universidad Nacional Autónoma de México. 
Hay temas que durante muchos años han constituido tabúes dentro de la literatura, lo que ha significado no sólo una producción reducida frente a otros tópicos sino también un escaso acercamiento de estudios y análisis de las obras. Tal es el caso de la homosexualidad, que concretamente en México comenzó a aparecer en los albores del siglo veinte; primero en la poesía, que permitió la ambigüedad entre sus juegos metafóricos, y luego en la narrativa.

Si bien hubo atisbos desde los años sesenta, la primera novela homosexual masculina reconocida en México es El vampiro de la olonia Roma, escrita por Luis Zapata, publicada en 1979 y ganadora del Premio Juan Grijalbo. D esde entonces, el tema de la homosexualidad masculina ha encontrado un lugar en la narrativa mexicana; en contraste, la primera novela lésbica, A mora de Rosa María Roffiel, se publicó hasta 1989, y ha sido una obra poco valorada en los estudios académicos no obstante el importante tiraje y las varias ediciones y reimpresiones, nacionales e internacionales, que ha conseguido. La literatura lésbica, en general, ha encontrado mayores enconos y censuras que la homosexual masculina, por ello son poco conocidos y difundidos los ecos narrativos de aquella obra lésbica inicial.

La relativa solidez y auge obtenidos a partir de los últimos años del siglo XX y los primeros del XXI han respondido, de alguna manera, a la creciente necesidad de organización y visibilidad de las mujeres homosexuales, quienes difuminadas frecuentemente en los grupos feministas y en las organizaciones homosexuales, con los que son afines, no habían manifestado su propia especificidad. Así pues, la historia del lesbianismo en la narrativa mexicana debe abordarse no sólo desde el análisis literario sino de las determinaciones sociales que han impulsado o censurado su desarrollo hasta nuestros días.

Lo que caracteriza a la literatura homosexual, en términos generales, y por tanto a la lésbica, no es el género de los autores ni su orientación sexual, como se podría pensar, sino la centralidad del tema, a partir de personajes que viven algún tipo de relación homoerótica, de manera eventual o como forma cotidiana de vida, sin que esto signifique necesariamente que asuman una identidad 
homosexual. En el Diocionario de literatura mexicana. Siglo X X , Angélica Tornero señala que "algunos críticos han dado en llamar literatura homosexual a aquella escrita por hombres y mujeres, homosexuales y heterosexuales que tratan el tema de manera explícita" (Tornero 211).

En términos generales, el principal antecedente literario del amor entre mujeres se encuentra en la obra de Safo de Lesbos, sin embargo, el precedente inmediato del tema en la literatura mexicana son las obras francesas, especialmente la de los poetas malditos, que asumieron el amor lésbico como una veta transgresora importante, una de todas las realidades humanas que los simbolistas buscaron exponer. En México, Efrén Rebolledo, influido por Baudelaire y Verlaine, entre otros, explorando distintas fuentes eróticas, creó quizá el primer poema lésbico mexicano: "El beso de Safo" contenido en $\mathrm{C}$ aro $\mathrm{V}$ idrix.

Más pulidos que el mármol transparente, más blancos que los vellocinos se anudan dos cuerpos femeninos en grupo escultórico y ardiente.

Ancas de cebra, escozos de serpiente, combas rotundas, senos colombinos una lumbre los labios purpurinos y las dos cabelleras un torrente

En el vivo combate los pezones que embisten, parecen dos pitones trabados en eróticas pendencias,

y en medio de los muslos enlazados dos rosas de capullo inviolados destilan y confunden sus esencias. 
La poesía fue, pues, el género en el que se dio cabida en principio a la homosexualidad femenina, aunque, hay que aclarar, como imagen de las fantasías eróticas varoniles en que la inocencia y castidad femeninas se conservan ante lo que consideran un acto que no puede causar "daño". Posteriormente Silvia Tomasa Rivera difuminó el tema en sus poemas, y Nancy Cárdenas en Cuaderno de amor y desamor, Rosamaría Roffiel en Corramos Libres ahora y Reyna Barrera en L unario lo hicieron al fin evidente.

A principios del siglo XX se reconoció la capacidad de las mujeres para la creación literaria, durante el gobierno de Lázaro Cárdenas surgieron las primeras novelistas, la mayoría con escolaridad elemental, otras fueron periodistas y otras más pertenecían a familias pudientes de provincia. En el medio siglo las mujeres que escriben suelen ser universitarias 0 estar vinculadas al medio académico, como Elena Garro y Rosario Castellanos, en los años sesenta y setenta Inés Arredondo se atrevió a incorporar el erotismo y la homosexualidad masculina y escritoras como Tita Valencia y Esther Seligson abordaron el tema del erotismo desde la mirada femenina. A partir de mediados de los sesenta las mujeres que se relacionan erótica, amorosa y sexualmente con otras mujeres comenzaron a figurar entre los personajes principales de las historias literarias, al principio sólo de las escritas por varones.

Quizá "la Gitadilla", prostituta enamorada de Santa en la obra del mismo nombre de Federico $G$ amboa, sea la primer referencia a una personaje homosexual en la narrativa mexicana; en esta novela de 1903 la homosexualidad femenina es una de las secuelas de la depravación y por tanto condición común entre las prostitutas. En años posteriores José Revueltas incluyó este mismo tipo de personajes en sus novelas, y finalmente Juan G arcía Ponce y René Avilés Fabila dan a la mujer homosexual el carácter de personaje central, aunque aún con un sesgo de reprobación o de fatalidad. Dice la contraportada del libro L a lluvia no mata las flores (1970) de Avilés Fabila, en el que se encuentra el cuento lésbico "El viento de la ciudad": 
[...] Las historias que componen este libro pertenecen al mundo secreto de las personas, a lo que avergüenza y trata de olvidarse 0 esconderse. Son sucesos anormales de gente que posee prejuicios en público, de buenas costumbres, convencional, en una palabra: decente. Casos anormales, sí, pero también justificables porque sacaron a esos seres de la monotonía y del aburrimiento para enfrentarlos a una realidad ineludible.

Beatriz Espejo quizá por primera vez en las letras femeninas mexicanas introduce en 1979 la posibilidad amorosa entre mujeres y, a diferencia de los textos de Avilés Fabila y García Ponce, las configura como personajes libres de consideraciones maniqueas 0 morales en su cuento "Las dulces", contenido en Muros de azogue, que es una historia que hace referencia al despertar candoroso de una mujer madura a una posibilidad amorosa distinta. Esta nueva visión no es gratuita, tiene tras de sí el surgimiento del movimiento feminista en México durante la década de los setenta, luego de la matanza estudiantil de 1968 y con él la emergencia de los temas sobre la sexualidad femenina y el control de la reproducción; la creación del Frente de Liberación Homosexual en 1971, cuya cara pública fue Nancy Cárdenas, la presentación de D edaración de las lesbianas de M éxico en la Conferencia Mundial del Año Internacional de la Mujer en 1975, y la creación en 1977 de Lesbos, un grupo feminista con posición socialista, considerado la primera organización lésbica en México, que sería la semilla para la creación de muchos grupos más con distintos matices e ideologías.

En este contexto Rosamaría Roffiel escribe en 1983 y publica en 1989 A mora, considerada la primera novela lésbica en México. En ella recrea el ambiente de los inicios de los años ochenta, y si bien no habla de grupos propiamente lésbicos, menciona la participación de las lesbianas en el movimiento feminista y refiere la creación del Movimiento de Liberación Homosexual en México. En el capítulo "Somos mujeres y nos gusta serlo" la protagonista dice al respecto: 
Para muchos, feminista es sinónimo de lesbiana. ¡Ojalá! Pero, ni todas las feministas son lesbianas, ni - desafortunadamente- todas las lesbianas son feministas. Si supieran qué lucha tan ardua para que muchas "compañeras feministas" aceptaran lesbianas dentro de sus propios grupos. No fuera que las confundieran [...] Para ellas fue un alivio cuando se organizó el Movimiento de Liberación Homosexual en México. De todas formas, la gente sigue con la idea. Y sí, algunas feministas somos lesbianas, o sea, somos mujeres que amamos a otras mujeres, o sea que en realidad también somos personas, uno de los dos géneros que conforman la humanidad, y miren, ¡qué casualidad!, nacemos, crecemos, nos reproducimos y morimos... igualito que el resto de la raza humana. (Roffiel 32-33)

La obra relata parte de la vida de G uadalupe, personaje central y narradora de la historia. Es veracruzana, tiene 28 años, periodista autodidacta, intelectual de izquierda, comprometida con el feminismo y con la lucha por la justicia para las mujeres violadas. A decir de la propia Rosamaría Roffiel en los agradecimientos, la historia tiene un gran contenido autobiográfico, casi todas las mujeres representadas existieron y casi todo ocurrió realmente. Está delimitada temporalmente por la relación amorosa entre Guadalupe y Claudia: se conocen, se enamoran, rompen, vuelven, se separan de nuevo y finalmente se reconcilian, por el conflicto interno de Claudia, quien hasta entonces se definía heterosexual.

Esta estructura central fluye linealmente, y en ella se entretejen las otras historias: la personal, su vida en familia, la adquisición de su independencia, su iniciación en el mundo lésbico, su trabajo como periodista, su labor en el Grupo de Ayuda a Personas Violadas, su incursión en el feminismo, y las semblanzas del grupo de amigas. La acción se desarrolla espacialmente en la ciudad de México y se sitúa históricamente a partir de las preocupaciones de Vica (una de las compañeras del Grupo de Ayuda a Personas Violadas), que son: 
la posible invasión de Nicaragua, la huelga de los trabajadores de la refresquera Pascual y el caso de Elvira Luz Cruz. ${ }^{1}$

A mora parece ser hasta nuestros días la obra más comprometida con una lucha por una reivindicación femenina y homosexual. A partir de esta novela han surgido otras, cargadas de erotismo 0 incluso sexualidad explícita, que buscan, en cambio, una identidad amorosa y literaria; que no escatiman en las posibilidades del amor lésbico, o en el que las mujeres que aman a otras mujeres relatan, sin más, su inserción en la sociedad. Aunque muchos de estos textos no manifiestan una adhesión al feminismo o al movimiento homosexual, los llevan implícitos como antecedente de su desarrollo, de la misma manera tácita en que guardan la historia de las mujeres en la literatura.

Los diferentes puntos de vista en los textos anteriores son evidentes; en cada una de estas obras, desde la perspectiva de la comunicación, un autor implícito intenta convencernos de algo. En primer lugar se nos quiere persuadir de la existencia de distintos mundos en los que mujeres aman a otras mujeres. De manera específica Figura de paja de Juan García Ponce tiene como eje principal el suicidio de Leonor luego que Teresa decide dejarla por un amigo de ambas. "El viento de la ciudad" de René Avilés Fabila pone al descubierto, en medio de una fiesta de jóvenes intelectuales, la hasta entonces oculta, oscura y tortuosa relación amorosa entre Lourdes y Yolanda. "Las dulces" de Beatriz Espejo induce a pensar que la homosexualidad es la respuesta a la pregunta que Lucero se hace en torno a cómo ser feliz. En estos tres textos el amor entre mujeres constituye una sorpresa para el lector, no obstante las señales que lo van conduciendo a su descubrimiento.

A mora coincide en cuanto al objetivo de persuasión con "Las dulces", puesto que plantea que para Claudia la homosexualidad puede llegar a ser una opción amorosa y satisfactoria válida, pero a

${ }^{1}$ Mujer mexicana que agobiada por la pobreza, la violencia de la cual es víctima y la ignorancia, mata a sus hijos. Su caso llamó la atención de los grupos feministas. 
diferencia de Lucero (quien se autodefine como una solterona conservadora), Claudia es una mujer en principio heterosexual que cree en las relaciones abiertas y con Guadalupe experimenta una experiencia distinta que finalmente trastoca sus valores. A diferencia de los textos anteriores, A mora no nos depara ninguna sorpresa, desde el principio sabemos que $\mathrm{G}$ uadalupe es homosexual y que Claudia no lo es, porque el texto lo dice claramente. El horizonte de expectativas corre, entonces, en este sentido: en ir tratando de vaticinar si Claudia dejará a sus amantes varones y qué pasará con sus propios prejuicios contra la homosexualidad.

Si bien en escasos cuentos y novelas publicados después de A mora se menciona la homosexualidad o el lesbianismo explícitamente, la sorpresa en torno al homoerotismo ha dejado de ser estrategia de persuasión. En cambio se han ido estableciendo otras afinidades en la narrativa lésbica, entre ellas la reinvención de mitos, los espacios exclusivamente femeninos y lésbicos, la reescritura de los cuentos infantiles, las historias de vida y la iniciación lésbica o el homoerotismo adolescente, tópicos recreados frecuentemente con un lenguaje coloquial, con humor y en estructuras narrativas sencillas.

A estos tópicos corresponden también diferentes puntos de vista conforme a posiciones socioeconómicas recreadas. Podemos distinguir tres puntos de vista que corresponden a la recreación de tres clases socioculturales: la más amplia variedad se sitúa en la recreación de la clase media intelectual, comenzando por Figura de Paja (1964) de Juan García Ponce, la historia de un triángulo amoroso entre dos mujeres y un hombre cuyo desenlace es trágico; "Vientos de la ciudad" (1969) de René Avilés Fabila, donde una pareja de mujeres tormentosas queda al descubierto en una fiesta de jóvenes intelectuales; Con fugitivo paso... (1997) de Victoria Enríquez, que son cuentos sobre la reinvención de los mitos fundacionales de la sociedad, y del amor entre mujeres; Sandra. Secreto de A mor de Reyna Barrera (2001), que relata una historia amorosa en el marco del Festival Cultural Cervantino; de Roffiel, A mora y E 1 para siempre dura una noche... (2002), este último libro de cuentos, algunos sobre el amor entre mujeres y uno muy especial: la historia que se le relata 
a un niño para que duerma, de cómo se conocieron sus mamás, a manera de un cuento de hadas; V oces sueños y musas (2004), coordinada por Alein Ortegón, es una antología de cuentos escritos por integrantes del grupo lésbico El Clóset de Sor Juana.

O tras obras son ambientadas en espacios de nivel socioeconómico alto, entre ellas: D os mujeres de Sara Levi (1990), que narra los goces del amor homosexual pero también la incomprensión y la feroz represión de que es capaz una familia judía; Infinita de Ethel Krauze (1992) insinúa nuevamente un triángulo entre un violinista, su esposa y una amiga cercana. "Concierto a cuatro manos" de Aline Petterson (1992) construye un juego erótico entre adolescentes en el salón de clases a partir de la historia que imaginan sobre una joven cristiana raptada por los moros, y las caricias que se prodigan bajo el pupitre; Réquiem por una muñeca Rota (2000), novela de Eve Gil que habla del descubrimiento amoroso de dos colegialas y La casa de la magnolia de Pedro Ángel Palou (2004), novela sobre el amor entre una mujer madura y una joven.

Finalmente, el menor número de obras está inserta en el espacio socioeconómico bajo: Sonatina de Rosina Conde (2001) en cuya trama una mujer "masculina" defiende y procura a una prostituta en un burdel, la saca de su ambiente y pretende tenerla como ama de casa. Y E 1 callejón de las vírgenes de Safo de Susana Q uiroz e Inés Morales, libro editado por el Colectivo de Mujeres y Cultura Subterránea en un barrio popular mexicano reconocido por su pobreza: Ciudad Netzahualcóyotl. De entre cuentos de barrios y vampiros, escritos con poca intuición literaria, por su tema destaca "Cristina y Maira". Este narra la historia de dos chicas que son pareja, que viven en una coladera de la ciudad con un grupo de varones adolescentes y duermen entre los cables de alta tensión porque prefieren morir electrocutadas que ser violadas por sus compañeros cuando están bajo los efectos de la droga.

Como se puede observar, a partir de "Las dulces" de Beatriz Espejo el tema ha sido despojado del halo ominoso que le ceñía y sus múltiples posibilidades están siendo indagadas, sobre todo por escritoras, como una forma femenina de ser. 
Para concluir la literatura lésbica tiene como antecedente los movimientos feminista, homosexual y lésbico; manifiesta un recorrido que ha ido abriendo poco a poco la posibilidad de existencia social de los grupos sexuales marginados. En dicho recorrido las mujeres pudieron ser personajes centrales, después como escritoras pudieron hablar de sí mismas, de su vida, sus pensamientos y su propio erotismo, y ahora, también, estamos en el camino de construir una narrativa que hable del amor entre mujeres sin necesidad de personajes escabrosos ni finales fatídicos.

\section{Bibliografía}

Barrera, Reyna. Sandra. Secreto de amor. México: Plaza y Valdés, 2001. Enríquez, Victoria. Con fugitivo paso... Chilpancingo: s. e., 1997. Espejo, Beatriz. "Las dulces". Muros de azogue. México: Diógenes, SEP, 1986 (Lecturas Mexicanas Segunda Serie, 40).

Marquet, Antonio. iQ ue se quede el infinito sin estrellas! México: Universidad Autónoma Metropolitana-Azcapotzalco, 2001.

Mogrovejo, Norma. Un amor que se atrevió a dear su nombre. México: Plaza y Valdés, 2000.

Ortegón, Alein. V oces, sueños y musas. A ntología lésbica. México: Inmujer-D. F./ El Clóset de Sor Juana, 2004.

Petterson, Aline. "Concierto a cuatro manos". A trapadas en la cama. Eds. Beatriz Espejo y Ethel Krauze. México: Alfaguara, 2002. Palou, Pedro Ángel. La casa de la magnolia. México: Sudamericana, 2004.

Q uiróz, Susana e Inés Morales. E 1 callejón de las vírgenes de Safo. México: Mujeres y Cultura Subterránea, 2002.

Robles, Martha. La sombra fugitiva. E scritoras en la Cultura $\mathrm{N}$ acional. México: UNAM, 1985.

Roffiel, Rosamaría. A mora. México: Planeta, 1990 [1a. ed., 1989. También publicada en Madrid (Horas y Horas) y en México (Sentido Contrario). 
El para siempre dura una noche. México: Sentido Contrario, 2002.

Tornero, Angélica. "Literatura homosexual". Temas y variaciones de literatura 17 (2001).

Trejo Fuentes, Ignacio. "Rosamaría Roffiel: A mora". Temas y variaciones de literatura 17 (2001). 